\title{
Hard paths, soft paths or no paths? Cross-cultural perceptions of water solutions
}

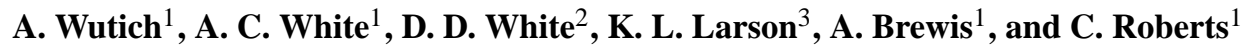 \\ ${ }^{1}$ School of Human Evolution and Social Change, Arizona State University, Tempe, USA \\ ${ }^{2}$ School of Community Resources and Development, Arizona State University, Tempe, USA \\ ${ }^{3}$ School of Geographical Sciences and Urban Planning and School of Sustainability, Arizona State University, Tempe, USA
}

Correspondence to: A. Wutich (amber.wutich@asu.edu)

Received: 31 May 2013 - Published in Hydrol. Earth Syst. Sci. Discuss.: 20 June 2013

Revised: 15 November 2013 - Accepted: 1 December 2013 - Published: 13 January 2014

\begin{abstract}
In this study, we examine how development status and water scarcity shape people's perceptions of "hard path" and "soft path" water solutions. Based on ethnographic research conducted in four semi-rural/peri-urban sites (in Bolivia, Fiji, New Zealand, and the US), we use content analysis to conduct statistical and thematic comparisons of interview data. Our results indicate clear differences associated with development status and, to a lesser extent, water scarcity. People in the two less developed sites were more likely to suggest hard path solutions, less likely to suggest soft path solutions, and more likely to see no path to solutions than people in the more developed sites. Thematically, people in the two less developed sites envisioned solutions that involve small-scale water infrastructure and decentralized, community-based solutions, while people in the more developed sites envisioned solutions that involve large-scale infrastructure and centralized, regulatory water solutions. People in the two water-scarce sites were less likely to suggest soft path solutions and more likely to see no path to solutions (but no more likely to suggest hard path solutions) than people in the water-rich sites. Thematically, people in the two water-rich sites seemed to perceive a wider array of unrealized potential soft path solutions than those in the waterscarce sites. On balance, our findings are encouraging in that they indicate that people are receptive to soft path solutions in a range of sites, even those with limited financial or water resources. Our research points to the need for more studies that investigate the social feasibility of soft path water solutions, particularly in sites with significant financial and natural resource constraints.
\end{abstract}

\section{Introduction}

Around the world, water managers are increasingly embracing "soft path" approaches - including water conservation, efficiency, and reallocation - to ensure that people have the water they need in the future. Yet, as Pahl-Wostl et al. (2008) argue, water solutions that rely on social engineering (in addition to hydrologic engineering) will require a more nuanced understanding of human attitudes, beliefs, and behaviors. In this ethnographic study, we use interviews with local community members in four global sites to ask three key questions: (1) how do people conceptualize water solutions (hard paths, soft paths, no paths) cross-culturally? (2) What role does development status play in shaping how people conceptualize water solutions? (3) What role does water scarcity play in shaping how people conceptualize water solutions? Building on the work of Gleick (2003), Brooks and Holtz (2009), and Brandes et al. (2009), our goal is to contribute to nascent theories of how socio-economic and environmental conditions shape people's views toward hard path and soft path water solutions cross-culturally.

\subsection{Hard paths and soft paths}

Historically, water management has focused on building and managing water supply infrastructure to meet human water demands. This approach brought into use large-scale, centralized water infrastructure including major systems for flood control, irrigation, water treatment, municipal water distribution, sewage systems, and water storage. Known as the "hard path", this approach to water management has improved human water security around the world (Gleick, 
2002, 2003). Yet the overallocation of freshwater resources - and diminishing capacity of the hard path approach to solve emerging water problems - led water managers to seek new approaches. Brooks (1993) and Gleick (1998) proposed a shift from approaches that emphasize finding new water supplies to those that manage water demand and scarce resources more effectively. This has come to be known as the "soft path". Soft path solutions, which focus on reforming institutions (such as water policies and regulations), improving water-efficient technologies, and managing agricultural and residential water usage, can address the threat of future water scarcity when hard path approaches have not (Gleick, 2002).

While water managers' receptiveness to soft path solutions has been well-documented (e.g., Brown et al., 2009; Ahmed, 2009; Jacobs and Turton, 2009; Brooks, 2009c; Wade, 2012), less research has investigated popular views of these water management strategies. Yet many soft path solutions rely on public awareness, participation, and behavior change (Jordaan et al., 2009). Soft path solutions have long emphasized the importance of public participation in decision-making. To increase the likelihood that soft path solutions will be successful, it is important to understand what factors shape their public acceptability (Pahl-Wostl et al., 2008; Larson et al., 2009). Brooks (2009a, b) has proposed that two key factors might shape receptiveness to soft path solutions cross-nationally: development status and water scarcity.

\subsection{Development status}

Development status is a complex concept that encompasses national wealth, government debt, institutional fragility, and health and education status (World Bank, 2013a). Critics of the development concept highlight its tendency to aggregate inappropriately highly diverse countries and obfuscate the roles of colonization and exploitation in creating contemporary poverty (Shakow and Irwin, 2002). While we agree with this critique, we argue that development status continues to be a useful analytic construct because it allows us to explore how national histories of colonization, inequitable global power structures, and stymied economic growth impact the lived experiences of citizens across diverse contexts.

In the water realm, more and less developed countries can differ drastically in terms of built infrastructure, technological complexity, economic dependence on water, and individual water allotments. Because more developed countries often have geographically extensive and technologically advanced infrastructure, Brooks (2009a, p. 207) proposed that these countries might be more receptive to soft path solutions. Examples of such successes include the implementation of market mechanisms to reshape water consumption in Australia (Bjornland and Kuehne, 2009) and cost recovery for water services in the member nations of the European Union (Klawitter, 2009). In comparison, less developed countries face significant water challenges, such as large populations who lack stable access to safe water sources, which might be addressed by major investments in hard path infrastructure. As a result, less developed countries might be seen as more receptive to hard path solutions (Brooks, 2009 b, p. 229). Yet, development aid to expand water infrastructure is declining globally - and the smallest share goes to the neediest countries (Gleick, 2003). As an alternative to hard path solutions, soft paths might be considered an important part of the toolkit that people already use to address water problems in developing countries (e.g., Brooks, 2009b). For instance, residents of less developed countries often have strong community governance institutions, hands-on experience managing water at the community level, and local ecological knowledge of water systems (Ostrom, 1990; Berkes et al., 2000). If so, residents of such countries might be more receptive toward soft path solutions - and more capacitated to execute them successfully - than many currently assume.

A major goal of this study is to determine if respondents in more developed sites deem soft path solutions more feasible or desirable than in less developed sites. Specifically, we hypothesize that: (1) respondents from more developed sites are more likely to suggest soft path solutions, (2) respondents from less developed sites are more likely to suggest hard path solutions, and (3) respondents from less developed sites are more likely to suggest no paths to solutions. Additionally, we propose to explore whether or not the quality or type of soft path solutions proposed differs depending on development status.

\subsection{Water scarcity}

Water scarcity is a multifaceted concept, which may include physical scarcity, economic scarcity, and unmet ecological needs, among other dimensions (Seckler et al., 1999; Rijsberman, 2006). Here we concentrate on two dimensions of water scarcity: physical and economic. When water is physically scarce, a country or region does not have enough water to meet its population's water needs. When water is economically scarce, a country or region has enough water but lacks the infrastructure to physically distribute it to meet the population's water needs. Both forms of water scarcity could potentially affect the acceptability of hard and soft path solutions.

Brooks (2009a, b) speculated on the ways in which water scarcity might facilitate or impede the success of soft path solutions. In cases where water availability is adequate but declining, Brooks (2009a, p. 207) suggests that water scarcity might facilitate public acceptance of soft path solutions. In the water-rich northeastern US, for instance, conservation-oriented water rates were implemented to address urban water demand during a drought. The new water rates improved efficiency in socially equitable ways that also improved ecosystem function (Smith and Wang, 2007). In cases where water availability is inadequate, Brooks (2009b, 
p. 229) suggests that the need to find new sources and extend water delivery infrastructure might make hard path solutions more desirable than soft path solutions. Yet some proponents of soft path solutions argue that they can help solve water problems in regions facing physical water scarcity, economic water scarcity, or both. Water experts, for instance, see a role for soft path solutions in water-scarce sites in India (Ahmed, 2009), South Africa (Jacobs and Turton, 2009), the western US (Gober and Kirkwood, 2010), the Middle East (Brooks, 2009c) and Latin America (Wade, 2012). It remains to be seen if people on the ground share the experts' vision for reforming their water systems.

Following Brooks, a primary goal of this study is to determine if respondents in water-rich sites deem soft path solutions more feasible or desirable than water-scarce sites. Specifically, we hypothesize that: (1) respondents from water-rich sites are more likely to suggest soft path solutions, (2) respondents from water-scarce sites are more likely to suggest hard path solutions, and (3) respondents from waterscarce sites are more likely to suggest no paths to solutions. Additionally, we explore whether or not the quality or type of soft path solutions proposed differs depending on local water availability.

\section{Case selection}

For this research, we selected community sites in four countries to facilitate comparisons related to the key dimensions of development status and water scarcity. We chose the four cases based on theoretical replication (Yin, 2009), which enables us to compare between cases with high and low development and water scarcity. We selected: a site in Bolivia to represent an economically developing, water-scarce setting; a site in Fiji to represent an economically developing, water-rich setting; a site in New Zealand to represent an economically developed, water-rich setting; and a site in the $U S$ to represent an economically developed, water-scarce setting. To enhance cross-site comparability, we conducted interviews in each site with residents of a semi-rural or periurban community. Each of the focal sites has a patchwork of water delivery infrastructure including a publicly administered water system, groundwater wells, and/or surface water collection. In each locale, there is controversy over the nature of past and planned institutional reforms, including the development or expansion of community water systems.

\section{Methods}

\subsection{Data collection}

The sampling strategy used in each site was purposive, as is typical in qualitative research (Bernard and Ryan, 2010). The sample was designed to capture only local residents, as they are likely to share environmentally relevant local cultural and institutional knowledge. Current guidelines for qualitative research establish that 12-20 participants are needed to identify core themes (Guest et al., 2006; Bernard and Ryan, 2010). We exceeded this minimum in each site to ensure that, in addition to identifying core themes, our sample was large enough to allow us to identify subthemes and periphery themes. We collected data with 135 respondents: 41 in Bolivia, 37 in Fiji, 27 in New Zealand, and 30 in the US.

The data collection was conducted through face-to-face interviews in each field site. Ethnographic experts (Wutich in the Bolivia and US sites, Brewis in the Fiji and New Zealand sites) oversaw the fieldwork, including interviewer training, participant recruitment, informed consent, data entry, and data quality checks. Interviews were conducted in the native language of participants (Spanish in Bolivia, English in New Zealand and the US, and English with Fijian translators, as needed, in Fiji). To enhance the comparability of responses, we used the same interview protocol and questions in each site. Survey translation and pre-testing were conducted to ensure the language equivalence of Spanish and English versions of the survey. We made minor changes to the protocols to ensure they were locally relevant and understandable (e.g., race and ethnicity categories were adopted from each country's national census questionnaire).

The interview protocol included questions on water institutions, water quality and availability, climate change, and basic respondent demographics. The section that produced the data we analyze here contained three open-ended questions. First, we elicited from each respondent a list of all of the local sources of water in their community. This yielded water sources such as "rainwater", "the Salt River", and a "borehole". Next, we asked respondents to name the threats to each water source. This question yielded responses such as "drought", "disease", "contamination", and "breakage in equipment". Finally, we asked respondents to name solutions or things that could be done to address threats to each of the water sources they named. This question yielded responses such as "build a nice tank" and "advertise water conservation". All probing was non-specific and non-directive (e.g., "Can you think of anything else?"). Interviewers recorded responses verbatim. These verbatim responses are the primary data that were analyzed in this study.

\subsection{Data analysis}

We analyzed our data using a content analysis approach (Krippendorf, 2012). We began our analysis by identifying key concepts from the literature on water solutions (i.e., hard paths and soft paths). After a preliminary analysis of the data, we introduced one additional code: "no paths". Based on our own inductive analysis of the hard path and soft path themes, we found that this third code - while only implicit in the literature on soft paths - was needed to capture an important stream of variability in the data. 
Table 1. Study site characteristics.

\begin{tabular}{|c|c|c|c|c|}
\hline & Cochabamba, Bolivia & Viti Levu, Fiji & PioPio, New Zealand & Phoenix, US \\
\hline National GDP per capita ${ }^{1 \mathrm{a}}$ & $\$ 2575$ & $\$ 4438$ & $\$ 37749$ & $\$ 49965$ \\
\hline National poverty rate $(\%)$ & $50^{2 \mathrm{a}}$ & $31^{2 b}$ & $15^{3}$ & $15^{2 \mathrm{a}}$ \\
\hline National life expectancy ${ }^{1 b}$ & 66.6 & 69.6 & 80.9 & 78.6 \\
\hline Constitution established & 1826 & 1970 & 1852 & 1789 \\
\hline National government ${ }^{2}$ & Republic & Republic & Parliamentary democracy & Federal republic \\
\hline Research site rurality ${ }^{5}$ & Peri-urban & Semi-rural & Semi-rural & Peri-urban \\
\hline Regional water scarcity 4 & Economic & None & None & Physical \\
\hline Local water governance 5 & $\begin{array}{l}\text { Highly democratic } \\
\text { and participatory }\end{array}$ & $\begin{array}{l}\text { Highly democratic } \\
\text { and participatory }\end{array}$ & $\begin{array}{l}\text { Democratic, largely } \\
\text { non-participatory }\end{array}$ & $\begin{array}{l}\text { Democratic, largely } \\
\text { non-participatory }\end{array}$ \\
\hline Recent water conflicts 5 & Development protests & Industrial tax dispute & Legislative disputes & Legislative disputes \\
\hline
\end{tabular}

We then created code definitions designed to allow us to classify free-flowing text into theoretically relevant categories in a valid and reliable fashion (Bernard and Ryan, 2010). Our codes included a basic definition, inclusion and exclusion criteria, and typical and atypical exemplars from each site (MacQueen et al., 1998). We pre-tested and revised codes, and tested inter-rater agreement using Cohen's kappa (Cohen, 1960). For the three codes, inter-rater agreement was very good or better $(\kappa>.75)$ in all cases: for hard paths, $\kappa=.76$; for soft paths, $\kappa=.79$; for no paths, $\kappa=.80$.

Coding units were defined as any distinct solution identified by a respondent. In total, we coded 630 statements about water solutions. Codes were mutually exclusive, meaning that each statement could be coded: [hard path OR soft path OR no path]. If a threat or solution could not be classified within these categories (e.g., it was too vague), it was excluded from the analysis. In addition to the thematic coding, we also coded the data to indicate whether the respondent resides in (1) a more or less economically developed country (based on World Bank, 2013a) and (2) a site that is or is not water-scarce (based on IWMI, 2007, p. 11).

We then analyzed the coded data for site-specific themes and cross-site trends. First, we grouped coded statements by site to facilitate the identification of site-specific themes dealing with hard paths, soft paths, and no paths. Site-specific themes were identified by a primary and secondary coder to ensure reliability. In the results, we discuss core themes (broad themes present in many narratives), subthemes (distinct threads of meaning within core themes), and periphery themes (mentioned by small clusters of respondents).

Second, we examined the coded results to identify crosssite trends related to development status. We conducted chisquared tests for independence to test our hypotheses regarding development status and paths to water solutions. To explore how the type of solutions proposed differs depending on development status, we conducted qualitative comparisons to identify differences in the presence, strength, or meaning of themes related to hard, soft, and no paths across the two conditions.

Third, we examined the coded results to identify cross-site trends related to water scarcity. We conducted chi-squared tests for independence to test our hypotheses regarding water scarcity and paths to water solutions. To explore how the type of proposed solutions differs depending on water scarcity, we conducted qualitative comparisons to identify differences in the presence, strength, or meaning of themes related to hard, soft, and no paths across the two conditions.

\section{Results}

\subsection{Hard, soft, and no paths: site-specific themes}

\subsubsection{Bolivia site}

In Bolivia, we collected data with residents of peri-urban squatter settlements in the semi-arid city of Cochabamba. Cochabamba is known to many as the site of the "Water War of 2000" over privatization. After the municipality regained control of the water system, many of Cochabamba's old problems persisted. Today, squatter settlements in Cochabamba largely lack stable access to municipal water. During the brief wet season, squatters collect rain and river water. Some squatter settlements own and operate small-scale water systems, but output is minimal due to low rainfall and inaccessible groundwater. Most squatters purchase higher-priced, lower-quality water from privately owned tanker trucks. Poverty, water scarcity, hunger resulting from water scarcity, and waterborne disease are common in these communities. 
Many of the Bolivian respondents pointed to hard path solutions for a various water problems, including: too little water, inadequate infrastructure, and dirty or contaminated water. The most common core theme was the need to build better water delivery infrastructure. One subtheme dealt with the need to build tanks to store water. People said, for example, "make a tank" and "we should make a tank". A second subtheme was building water distribution infrastructure. Examples of such comments were, "put in tubes", "make pipelines", "build canals", and "put in taps". A third subtheme dealt with building wells. People stated, for instance, "dig a well" and "make a well with construction workers and cement". A final subtheme was infrastructure to protect water from sources perceived to be pure, such as springs. For instance, respondents wanted to "cover the source very well" and "build a little house to protect springs".

Soft paths were primarily conceptualized in the Bolivia site as helpful for improving water quality. The most common theme emphasized the importance of restricting dumping and littering. People said, for instance, "don't contaminate", "don't dump chemicals", and "keep animals out". A few also mentioned the need to "have people whose job it is to protect the water". One subtheme addressed the need to safeguard water sources and infrastructure from disease, insects, animals, and other contaminants. Respondents suggested, for example, "cleaning tanks" and "cleaning wells". Another subtheme discussed the need to purify water that had been contaminated. Common suggestions included "boil water", "let the water settle", and "add something - like chlorine - so that it's not so dirty". A peripheral theme mentioned by some was the need to shift water uses to utilize existing sources more effectively. One example of this was to use river water "only for irrigation; it's unfit for washing". Another was the suggestion to "wash away from the river, in a large tub, and dispose of their water away from the river" to avoid contaminating river water.

A large number of respondents in the Bolivia site indicated that there was no path to protect water sources. Many people noted that rivers are "dirty", "contaminated", and "people throw in garbage" and "[dead] dogs". In answer to the question what can be done to address this contamination, however, many responded, "we can't do anything". Regarding the threats of flooding and drought, too, many people said, "there is nothing we can do" and "we just have to endure it". People gave similarly discouraging answers regarding threats posed by drought, pollution and microbial disease. These answers reflected the seriousness of problems and dearth of solutions in a less developed and water-scarce site like this one.

\subsubsection{Fiji site}

In Fiji, we interviewed residents of a semi-rural indigenous village on the south coast of the main island of Viti Levu. Water is generally abundant and available via springs, streams, rivers, and rainfall. In the past, failed development projects had left the community embittered and without adequate water infrastructure. Today, the village owns and administers its own small water system. With international aid, the village recently upgraded its infrastructure to improve water supply (e.g., new pipes, tanks, and residential connections) and sanitation (e.g., wastewater treatment). Water quality and waterborne disease remain serious problems.

People in the Fiji site suggested hard path solutions to water quality issues including pollution, dead animals, insects, brackish water, and waterborne disease. The common core theme was the need for infrastructure construction, expansion, or updates. One subtheme dealt with the need for more water infrastructure development generally. People said, for example, "build a proper system", "upgrade the water system", and add more "water projects". A second subtheme was the need for improved water tanks. People said, for instance, "build proper tanks", "build a nice tank or container", and "store water in water tanks". A third subtheme dealt with building water purification infrastructure. An example of this theme is: "build a proper purifying system". A final subtheme was the need to improve or update existing infrastructure. Examples included "make a block around the well" and "make a filter on top of the tank". A peripheral concern was the "drying of the reservoir"; the hard path solution suggested was to "build more reservoirs".

Soft path solutions suggested in the Fiji site were also focused almost exclusively on addressing water quality problems. The most common theme among the soft path solutions was "boil water" or "boil water before drinking it", which was seen as the solution to a range of waterborne disease threats including "skin disease", "stomachache", and "diarrhea". Another very common theme addressed the need to change livestock farming practices to protect water sources from "animal waste" and "farming fertilizers." Subthemes included "fence the spring", "tie up animals away from the water", "build pig pens away from rivers", and "tell farmers not to use excessive fertilizers". A final core theme emphasized the need to "not pollute" and "stop dumping rubbish in the river". Two subthemes highlight different views on locally appropriate approaches to stop littering. The first subtheme reflects Fijian villagers' commitment to self-governance and decision-making through consent-building. In this subtheme, people said, for example, "talk to everyone", "educate people of the harm" in littering, "let them know not to abuse" the spring, and "ask the village" to address problems. The second subtheme addresses the need for more government regulation of environmentally harmful behaviors. Examples include: "government laws", a "law to fine people who burn rubbish", and "limit the number of industries".

Few people expressed the opinion that there was no path to solving water problems. When people did not specify a path, it was typically because they felt that a water source faced "no threats". Some exceptions were problems mentioned only once: people overexploiting groundwater, nearby housing contaminating river water, and the possibility the 
desalinated ocean water might still be salty. In these few cases, people in the Fiji site were as likely to say "I don't know" how to solve a problem as they were to say "it can't be solved".

\subsubsection{New Zealand site}

In New Zealand, we interviewed residents of PioPio, a semirural farming community in the west-central region of the North Island. Piopio residents are primarily sheep and cattle farmers, though there is a small town center where people are employed through shops, tourism, and other services. In PioPio's town center, residents receive piped water service from a centralized public utility. In the farms located in the surrounding area, residents generally privately own and manage water from rainfall, local rivers, and springs. In New Zealand generally, water is abundant, water quality is excellent, and water access is currently universal - and expected to remain this way with adequate planning to address future challenges.

In the New Zealand site, only four respondents identified hard paths as a solution to water threats. Of those, the only clear theme to emerge was the need to build or improve dams to address natural disasters like flooding or earthquakes. The dearth of hard path solutions suggested by people in PioPio reflects the perceived adequacy of existing infrastructure.

In contrast, soft paths were preferred as solutions to a wide range of threats including giardia, invasive plants, effluent, pollution, drought, and climate change. The most salient theme was the need for more restrictions to safeguard water sources. One prominent subtheme dealt with regulation of farm runoff. Respondents suggested, for example, "strict control of fertilizer and chemicals", "restricting certain fertilizers", and "regulating farm capacity". Another major subtheme dealt with regulation of industrial and chemical pollution. For instance, respondents supported restrictions to make "more rules on chemical contamination", "increase pollution fines", and do more "regulation of big companies". A final subtheme dealt with regulation of tourist behavior. Examples included the need for "more regulations of skiers" to protect mountain water and "restrict[ing] gas power recreation, such as boats" to protect lakes. Related peripheral themes were the need for more fencing and monitoring. Respondents recommended, for example, "fencing off springs" and "fencing off rivers". Some were in favor of "fencing to keep livestock out" and "fencing of stock exits". Respondents also recommended monitoring a range of risks including "monitoring usage for overuse" and "monitoring recreation" to protect lakes. Another core soft path theme was education. One subtheme called for public education campaigns, such as "public education on good river practices". A second subtheme called for increased awareness, such as making "locals more aware" of threats to town supply. Several people also pointed to the necessity of making tourists aware of risks like "rock snot", or Didymosphenia geminata (didymo), an invasive freshwater plant discovered in New Zealand in 2004. A final core theme, which was present in many of the above themes, was reducing global warming. Respondents suggested that soft path solutions like restrictions (e.g., "less use of oil burning") and education (e.g., "global warming awareness") would be effective in protecting water sources threatened by climate change.

Only two respondents identified a water threat that they perceived to have no path to resolution. In both cases, the threat was drought. One respondent said, "Nothing can be done", while another said the solution was to "pray". The very small number of respondents identifying no paths is a reflection of New Zealand's rich economic and water resources, and people's confidence that solutions can be found for most water threats.

\subsubsection{US site}

In the US, we interviewed residents of Laveen, a peri-urban neighborhood in the desert city of Phoenix, Arizona. Recent studies indicate that water demand may eventually outstrip water supplies in Phoenix, particularly given the anticipated effects of climate change on water availability in the region (Gober and Kirkwood, 2010; Overpeck and Udall, 2010). One approach to obtain water for residential use is "agricultural retirement", or the transfer of farmers' water rights to residential users. Accordingly, lifestyles in historic farming communities like Laveen are changing radically. While some continue to farm and rely on wells drilled into their own land, Laveen is increasingly filled with suburban tract housing. To serve growing residential neighborhoods, Phoenix installed city water and sewage service for much of Laveen.

In the US site, people pointed to a handful of key hard path solutions for pressing water threats. One core theme was that, in order to protect water from the Colorado and Salt Rivers, there was a need to "build more dams" and "more reservoirs". Another theme suggested extending the Laveen sewage and stormwater systems (e.g., "a sewer line that we can connect to"). A third theme was filtration to address water contamination, including from "[garbage] dumps around town [that] leech things into the ground". Respondents suggested, for example, building "water treatment plants" and using "nanofiltering" and "reverse osmosis". A periphery theme suggested water managers should "route water underground to prevent evaporation" along the 336 mile $(541 \mathrm{~km})$ canal that connects the Colorado River to metropolitan Phoenix.

Respondents in the US site identified a number of soft path solutions to water threats. One of the largest core themes was regulation and restriction. One subtheme was rationing water use. Examples of this theme were: "ration water" and "limit human use". A related subtheme suggested limiting population growth to decrease water consumption. For example, one person said "quit building houses", while another suggested "limit the number of people who move here". A third subtheme dealt with putting "restrictions on abusive use 
of water". Examples of this were "limit swimming pools" and "golf courses shouldn't be watered". A final subtheme suggested regulating chemical use and limiting dumping. Examples included: "more strict rules about dumping chemicals" and "enforce environmental laws that we have". A second core theme was increased oversight and monitoring. People commented on the need for "broad-based oversight" to "monitor development", "monitor runoff", and "always be testing" water quality. A third core theme dealt with more voluntary measures, most often "conservation". A related subtheme was voluntary measures to limit pollution. This included measures such as "use earth-friendly chemicals" and do "not throw trash in the rivers". A final core theme addressed a range of alternative energy measures to slow fossilfuel pollution and climate change. Examples were: "clean coal" and "change energy usage". Education emerged only as a periphery theme, mentioned by two respondents, who indicated a need for "public information" and "water warnings".

Only three people in the US site felt that there was no path to addressing water threats. Two identified drought and a third identified bacteria as threats to water supply. In all three cases, they suggested that the only solution was to let nature take its course. One specifically named "mother nature". Another said, for instance, that a "couple of more high rainfall years" were needed.

\subsection{Development status and water scarcity: cross-site comparisons}

In this section, we compare views on hard paths soft paths, and no paths on two key conditions: development status and water scarcity.

\subsubsection{Development status}

Respondents from less developed sites were significantly more likely than those from more developed sites to suggest hard path solutions $\left(\chi^{2}=5.18, p=.02, \phi=.22\right)$. Beyond these quantitative differences, there were important qualitative differences across sites. Thematically, the hard path solutions suggested in less developed sites were more diverse - and dealt with a much wider range of problems - than in the more developed sites. In more developed sites, hard path solutions concentrated primarily on building more dams and reservoirs to safeguard against risks such as overpopulation and natural disasters. In contrast, respondents in less developed sites envisioned a wide range of water projects that were needed, including infrastructure for water storage (e.g., "build tanks") and treatment (e.g., "make a filter on top of the tank"). Additionally, it is noteworthy that the infrastructural projects proposed by respondents in the less developed sites tended to be at a much smaller scale (e.g., "put in tubes" or a "good pump") than in the more developed sites (e.g., "build dams" or "build a water treatment plant").
Respondents from more developed sites were significantly more likely than those from less developed sites to suggest soft path solutions $\left(\chi^{2}=6.50, p=.01, \phi=.25\right)$. Thematically, there were many similarities in the soft path solutions suggested across sites. Respondents in all sites were concerned about limiting pollution and improving water quality. The major differences are in the mechanisms people envision for accomplishing these goals. In the less developed sites, for instance, respondents focused primarily on behavioral changes (e.g., "clean wells" and "tie up animals") that are often implemented at the individual level. When respondents in the less developed sites did suggest cooperative solutions, they tended to be community-level initiatives (e.g., "hire caretakers" and "talk to everyone"). In contrast, respondents in the more developed sites were more focused on society-wide solutions that could be implemented through national government or, to a lesser extent, educational institutions. By far, the most dominant soft path theme in the more developed sites dealt with enacting more regulations (e.g., "better regulations on biohazard waste"), restrictions (e.g., "more restrictions on gasoline use"), and monitoring (e.g., "monitor runoff"). In both sites, too, respondents saw the reduction of global warming - through education in the New Zealand site (e.g., "global warming awareness") or alternative energy technologies in the US site (e.g., "create emissions-free airplane engines") - as an important soft path solution.

Respondents from less developed sites were significantly more likely than those from more developed sites to suggest there were no paths to water solutions $\left(\chi^{2}=5.19, p=.02\right.$, $\phi=.22$ ). In the developing sites, comments about the lack of paths to water solutions focused on people's inability to resolve water problems. One of the most common themes to emerge was that people did not know what solutions might be available or feasible (e.g., "we don't know" or "I don't know"). The use of "we" by many respondents is particularly significant, because it indicates that cooperative efforts have been made to address water threats but have not been successful in finding the information needed to resolve these problems. The other common theme was an expression of impotence when facing water problems (e.g., "we can't do anything", "it can't be solved", and "nothing because it's underground"). These answers imply that the resources to address problems may not exist at the community level. In contrast, relatively few people expressed the idea that there was no path to resolving water threats in the more developed sites.

\subsubsection{Water scarcity}

Respondents from water-scarce sites were no more likely to suggest hard path solutions than those from water-rich sites $\left(\chi^{2}=2.03, p=.15, \phi=.14\right)$. Despite the lack of quantitative differences, there was one salient qualitative difference. Thematically, respondents in water-scarce sites were more focused on the need to build infrastructure for transporting 
Table 2. Water solutions in four cross-cultural sites: a summary of themes, subthemes (in parentheses), periphery themes (in italics).

\begin{tabular}{|c|c|c|c|c|}
\hline & Cochabamba, Bolivia site & Viti Levu, Fiji site & PioPio, New Zealand site & Phoenix, US site \\
\hline $\begin{array}{l}\text { Hard } \\
\text { paths }\end{array}$ & $\begin{array}{l}\text { Build infrastructure } \\
\text { (Build water storage tanks) } \\
\text { (Build distribution infrastructure) } \\
\text { (Build wells) } \\
\text { (Cover water sources) }\end{array}$ & $\begin{array}{l}\text { Build infrastructure } \\
\text { (More water projects) } \\
\text { (Build water tanks) } \\
\text { (Build a purifying system) } \\
\text { (Update infrastructure) } \\
\text { Build more reservoirs }\end{array}$ & Build or improve dams & $\begin{array}{l}\text { Build dams \& reservoirs } \\
\text { Extend sewage systems } \\
\text { Build water treatment plants } \\
\text { Route water underground }\end{array}$ \\
\hline $\begin{array}{l}\text { Soft } \\
\text { paths }\end{array}$ & $\begin{array}{l}\text { Restrict dumping } \\
\text { Contract water caretakers } \\
\text { Clean tanks and wells } \\
\text { Purify contaminated water } \\
\text { Match water uses to quality }\end{array}$ & $\begin{array}{l}\text { Boil water } \\
\text { Change farming practices } \\
\text { (Fence the spring) } \\
\text { (Tie up animals) } \\
\text { (Build pens) } \\
\text { (Limit fertilizer use) } \\
\text { Stop polluting } \\
\text { (Consensus building) } \\
\text { (Laws and fines) }\end{array}$ & $\begin{array}{l}\text { Add more restrictions } \\
\text { (Limit farm runoff) } \\
\text { (Restrict industrial pollution) } \\
\text { (Regulate tourist behavior) } \\
\text { More fencing } \\
\text { More monitoring } \\
\text { More education } \\
\text { (Public education) } \\
\text { (Increase awareness) } \\
\text { Reduce global warming }\end{array}$ & $\begin{array}{l}\text { Add regulations and restrictions } \\
\text { (Ration water use) } \\
\text { (Limit population growth) } \\
\text { (Restrict overconsumption) } \\
\text { (Regulate chemicals/dumping) } \\
\text { Add oversight and monitoring } \\
\text { Voluntary measures } \\
\text { (Conservation) } \\
\text { (Limit pollution voluntarily) } \\
\text { Alternative energy } \\
\text { Education }\end{array}$ \\
\hline $\begin{array}{l}\text { No } \\
\text { paths }\end{array}$ & $\begin{array}{l}\text { We can't do anything } \\
\text { We just have to endure it } \\
\text { We don't know }\end{array}$ & $\begin{array}{l}\text { It can't be solved } \\
\text { I don't know }\end{array}$ & $\begin{array}{l}\text { Nothing } \\
\text { Pray }\end{array}$ & Let nature take its course \\
\hline
\end{tabular}

water than in the water-rich sites. For example, infrastructure to transport water ranged from "improve pipes" and "build canals" in the Bolivia site to "route water underground" and "smelt line them or pipe them to cut down on evaporation and seepage" in the US site. In contrast, no themes dealt with hard path solutions for water transport in the water-rich sites, as water resources are locally abundant in both cases.

Respondents from water-rich sites were much more likely to suggest soft path solutions than those from water-scarce sites $\left(\chi^{2}=19.65, p<.001, \phi=.42\right)$. The main thematic similarity between the soft path solutions in the water-rich sites was in the realm of farming. In both sites, respondents suggested numerous soft path solutions that dealt with changes to farming practices. In Fiji, soft path solutions were focused on restricting animal pollution of water sources (e.g., "move piggeries", "tie animals away from water", and "community can keep a lookout for stray animals"). In New Zealand, soft path solutions were focused on limiting the impacts of fertilizers and other chemicals used in farming on water sources (e.g., "correct usage of fertilizers", "safeguard leaching of fertilizers", and "safe application of agricultural chemicals"). While farming was also a part of daily life in both of the water-scarce sites, it was not perceived to a major threat to water sources. Instead, animal waste, fertilizer runoff, and agricultural water consumption played a relatively minor role in the wide range of water-related threats that respondents in water-scarce sites perceived. Another important thematic difference between respondents in water-rich and water-scarce sites dealt with water conservation and demand management. People in the water-scarce sites commonly suggested water conservation or demand management as soft path solutions, while those in water-rich sites did so rarely, if ever. In the Bolivia site, for example, demand management, especially regarding river water, was a salient theme (e.g., "don't use the river water for drinking; only for washing and irrigation"). In the US site, water conservation and rationing (e.g., "reduce use", "ration water", "emphasize conservation") and population growth limits (e.g., "limit swimming pools", "limit human consumption") were both clear themes. In addition, respondents in the US site repeatedly mentioned water pricing and cost as demand management mechanisms in another part of the interview protocol not analyzed here (see Wutich et al., 2013).

Respondents from water-scarce sites were significantly more likely than those from water-rich sites to suggest there were no paths to water solutions $\left(\chi^{2}=5.98, p=.02, \phi=.24\right)$. In water-scarce sites, comments about the lack of paths tended to express the idea that some water problems must be waited out. In the Bolivia site, examples of how respondents expressed this theme were: "we depend on God for [the rain] to come", "there is no way to divert or hold back [the rain]; it just comes", and "we just have to endure". In the US site, the theme manifested in terms of "let[ting] nature take its course", "water regeneration", and needing "a couple more high rainfall years". The only somewhat similar response from respondents in the water-rich sites was, in New Zealand, one person who said to "pray" in response to drought. 


\section{Discussion}

In this study, we examined narratives about water sources, perceived threats, and feasible solutions collected from sites in Bolivia, Fiji, New Zealand, and the US. We conducted thematic analyses in each site to understand local views of water solutions. In addition, we conducted statistical and thematic comparisons to determine the role that development status and water scarcity play in understandings of water solutions across the four sites. In this final section, we discuss the conditions under which people envisioned water solutions as hard paths, soft paths, or nonexistent (no paths) and the potential implications for future water management efforts in these sites and others like them. In particular, we highlight findings that may be useful for water mangers interested in implementing soft path solutions in diverse settings.

\subsection{Hard paths}

One of the clearest findings in this study was that people in our study's more and less developed sites conceptualize water solutions quite differently. Residents of the two more developed sites only suggested one type of infrastructural project - dams and reservoirs - to improve water security. In contrast, people in the two less developed sites were significantly more likely to suggest hard path solutions and, thematically, were focused on building the infrastructure necessary for basic water supply development, treatment, delivery, and waste disposal. This is clearly a result of the inadequacy of existing water infrastructure to meet basic human water and sanitation needs in these sites. As a social justice issue, underserved populations urgently need to be provided with infrastructure to ensure they have safe and secure water access. Water decision-makers, with the support of development banks, have made enormous progress in extending improved water sources to people around the world, and it is vitally important that this work continue.

Beyond this, it is also worth observing that the two less developed sites in this study (in Fiji and Bolivia) have historically been dependent on development aid from the governments and development agencies of the more developed sites (New Zealand and the US). This dependence on foreign governments and non-governmental organizations - for both financial aid and development priorities - may have constrained the exploration of alternative pathways toward development. Historically, development funding mechanisms have been biased toward funding engineering infrastructure as opposed to conservation, efficiency, and other soft path solutions. But this challenge may also represent an opportunity. Because of the continued influence of development agencies in water management, there is enormous potential for innovations in the design of water projects and water systems which, in many places, are being built from scratch - that are more equitable, efficient, and earth-friendly.
Water decision-makers (including those in development banks) have the opportunity to show leadership by modifying development aid mechanisms in ways that prioritize soft path solutions. Our findings indicate that there might be support for this in less developed sites like the ones we studied here. People in the two less developed sites almost universally envisioned new water infrastructure as small-scale, decentralized, and community-based (as compared to the large, centralized and state controlled infrastructure discussed in developed sites). Such infrastructure - including in-house connections and improved storage tanks - would be completely compatible with water managers' visions for soft path water systems. This would require some reform and innovation in the mechanisms by which development banks lend and monitor investments and the ways in which developing countries request assistance and report on success.

Water scarcity, in comparison to development status, was not strongly related to how people envisioned hard path water solutions across study sites. There was no statistically significant difference in hard path solutions suggested by people in the two water-scarce and the two water-rich sites, and the only thematic difference dealt with the need for infrastructure to transport water in water-scarce sites. Our findings are encouraging for water decision-makers who seek to implement soft path solutions because they suggest that people in water-scarce sites may be as willing as those in water-rich sites to move away from hard path solutions, though more research is needed to test this proposition definitively.

\subsection{Soft paths}

Our findings indicate that both development status and water scarcity are associated with how people conceptualize soft path solutions in important ways. People in the two waterrich sites were much more likely to suggest soft path solutions than those in the two water-scarce sites. We believe that the reason for this may be that people in water-rich sites had much greater potential to realize efficiency gains. In our study's water-rich sites, water historically has often not been conserved or used in efficient ways; people are now beginning to recognize the benefits of and need for water conservation. Our findings indicate that water decision-makers might find residents of water-rich settings, especially in sites that are just beginning to experience water stress, particularly receptive to soft path solutions.

While people in the two water-scarce sites were less likely to suggest soft-path solutions overall, they did suggest more soft paths related to water conservation, demand management, and pricing than residents of the water-rich sites. In both of our study's water-scarce sites, efficiency has long been part of local water management - though in very different ways. In the Bolivia site, for instance, many households survive with as little as $15-50 \mathrm{lpcd}$. As a result, most households are already heavily engaged in water conservation, matching water uses to quality, and reusing greywater 
and have no viable options to further reduce their water consumption. In the US site, institutional innovations have historically been used to manage water in ways that prioritize societal goals (e.g., as in the shift from farming to residential water use) and long-term water needs (e.g., water rate structures that encourage conservation). Thus, residents of water-scarce sites may be less likely to suggest soft path solutions because they have already experimented with and adopted many locally acceptable solutions for increasing water efficiency and conservation. This does, of course, represent a challenge for water decision-makers seeking to implement stricter or less socially acceptable soft path solutions in these sites. However, one positive aspect of these findings is that they indicate some support in water-scarce sites, even for soft path solutions that are generally less popular (e.g., block pricing, restricting water uses).

We also found that people in the two more developed sites were more likely to suggest soft path solutions than people in the two less developed sites; yet we believe that the thematic differences we uncovered are potentially much more significant to future efforts to realize soft path solutions. We found that people in the two less developed sites tended to suggest individual and community-based soft path solutions, while people in the two more developed sites tended to suggest regulatory, educational, and technological solutions. These thematic differences can largely be explained by differences in governance capacity across the less and more developed sites. In the two less developed sites, cooperative, community-level institutions are quite strong, and have long been actively involved in water management. In the two more developed sites, there are sophisticated, complex, and effective mechanisms for national-level water governance and educational initiatives. Our analysis does not allow us to determine what motivations drive people in more or less developed sites to suggest solutions at a particular scale (e.g., a preference for some forms of governance vs. disillusionment with other forms of governance). Ultimately, as van der Zaag and Gupta (2008) argue, "water storage and the institutional capacity to effectively administer it are recursively linked". Strengths in local and national scale governance offer unique, though different, opportunities. In less developed sites, water decision-makers can easily partner with local institutions to implement soft path solutions at the community level. In more developed sites, decision-makers can use strong national institutions to enact regulations and education programs to facilitate soft path solutions. While tactics may differ, there are potential pathways to soft path solutions in both settings.

\subsection{No paths}

Compared to hard and soft path solutions, comments indicating that there is no path to water solutions were relatively rare across the four cross-cultural sites. However, there was clear evidence that residents of our study's less developed and water-scarce sites were more likely to perceive no path. In the two less developed sites, people's statements indicated that they lacked the information and resources they needed to confront water problems. This is likely a result of the severity of water threats people face - and the dearth of resources available to address them in the foreseeable future - in our study's less developed sites. In the two water-scarce sites, people's statements indicated that some water problems could only be resolved by natural ecological processes (or their perceived agents, such as Mother Nature or God). This is likely due to people's experiences with drought - a water problem which is fairly impervious to behavioral, institutional, and infrastructural solutions and is more common in the water-scarce sites. In all of these cases, uncertainty appears to play an important role in shaping people's belief that there are no paths to water solutions. In the two waterscarce sites, uncertainty about climatological processes was most salient, while in the two less developed sites, uncertainty about the feasibility and efficacy of water solutions was more common. The role of uncertainties in decisionmaking among local residents and actors is a key area for future research.

There are several limitations which should be considered in the interpretation of these findings. First, this study relies primarily on thematic comparisons of a small number of cases. As such, its primary strength is in identifying trends that may push forward our understanding of cross-cultural views toward water solutions. To definitively establish that the differences identified here actually exist, it would be necessary to conduct confirmatory research with a much larger number of cases. Second, the two water-scarce sites selected in this study differ in that, according to the IWMI classification system we used to guide site selection, the US site has only physical (not economic) water scarcity, while the Bolivia site is dealing primarily with economic (not physical) water scarcity. This limitation, however, would be present in any study that examined water-scarce sites that are both more and less developed - as, globally, there are currently no developed countries that are reported to have economic water scarcity. As water scarcity classification systems become more nuanced, however, we believe that "hidden" pockets of water scarcity will become more widely recognized - even in the context of highly developed countries (e.g., Wescoat et al., 2007). Third, the two less developed sites selected for this study have both had mixed success with water development, but water projects initiated in the Fiji site have been more successful than the Bolivia site in the recent past. Responses would likely have been different if we had selected less developed sites that had a history of highly successful projects (e.g., less likely to say no paths) or highly unsuccessful projects (e.g., more likely to say no paths). Given these limitations, our research points to the need for more studies that investigate the social feasibility of soft path water solutions, particularly in sites with significant financial and natural resource constraints. 


\section{Conclusions}

In this study, we examined how development status and water scarcity shape people's receptiveness to hard and soft path solutions in four cross-cultural sites. Our results indicate some very clear differences based on development status and, to a lesser extent, water scarcity. People in our study's two less developed sites were more likely to suggest hard path solutions, less likely to suggest soft path solutions, and more likely to see no path to solutions than people in more developed sites. Additionally, people in the two less developed sites envisioned solutions that involve small-scale water infrastructure and decentralized, community-based initiatives, while people in the two more developed sites envisioned solutions that involve large-scale infrastructure and centralized, regulatory water solutions. People in our study's two waterscarce sites were less likely to suggest soft path solutions and more likely to see no path to solutions (but no more likely to suggest hard path solutions) than people in water-rich sites. People in our study's two water-rich sites seem to perceive a wider array of unrealized potential soft path solutions. On balance, our findings are encouraging in that they indicate that people are receptive to soft path solutions in a range of sites, even those with limited financial or water resources.

Acknowledgements. This research was conducted as part of the Global Ethnohydrology Study, a multi-year, multi-sited study designed to examine water norms and knowledge cross-culturally. We received funding under National Science Foundation award SES-0951366 (Decision Center for a Desert City II: Urban Climate Adaptation), National Science Foundation awards BCS-1026865 and DEB-0423704 (Central-Arizona Phoenix Long-term Ecological Research), and the Arizona State University Late Lessons from Early History initiative. We thank our research collaborators, interviewers, and participants in each site for their contributions to the study.

Edited by: V. Srinivasan

\section{References}

Ahmed, S.: Soft Path Thinking in Developing Countries: India, in: Making the Most of the Water We Have: The Soft Path Approach to Water Management, London, UK, Earthscan, 234-241, 2009.

Berkes, F., Colding, J., and Folke, C.: Rediscovery of Traditional Ecological Knowledge as Adaptive Management, Ecol. Appl., 10, 1251-1262, 2000.

Bernard, H. R. and Ryan, G. W.: Analyzing Qualitative Data: Systematic Approaches, Sage, Thousand Oaks, CA, 2010.

Bjornland, H. and Kuehne, G.: Soft Path Thinking in Other Developed Countries: Australia, in: Making the Most of the Water We Have: The Soft Path Approach to Water Management, Earthscan, London, UK, 218-226, 2009.
Brandes, O. M., Brooks, D. B., and Gurman, S.: Why a Soft Water Path, and Why Now, in: Making the Most of the Water We Have: The Soft Path Approach to Water Management, Earthscan, London, UK, 3-22, 2009.

Brooks, D. B.: Adjusting the Flow: Two Comments on the MiddleEast Water Crisis, Water Int., 18, 35-39, 1993.

Brooks, D. B.: Soft Path Thinking in Other Developed Economies (Editor's Note), in: Making the Most of the Water We Have: The Soft Path Approach to Water Management, Earthscan, London, UK, 207-208, 2009a.

Brooks, D. B.: Soft Path Thinking in Developing Countries (Editor's Note), in: Making the Most of the Water We Have: The Soft Path Approach to Water Management, Earthscan, London, UK, 229-230, 2009b

Brooks, D. B.: Soft Path Thinking in Developing Countries: Middle East and North Africa, in: Making the Most of the Water We Have: The Soft Path Approach to Water Management, Earthscan, London, UK, 242-254, 2009c.

Brooks, D. B. and Holtz, S.: Water soft path analysis: from principles to practice, Water Int., 34, 158-169, 2009.

Brown, R., Farrelly, M., and Keath, N. Practitioner perceptions of social and institutional barriers to advancing a diverse water source approach in Australia, Water Resour. Develop., 25, 1528, 2009.

CIA: World Factbook, https://www.cia.gov/library/publications/ the-world-factbook/ (last access: January 2014), 2013.

Cohen, J: A coefficient of agreement for nominal scales, Educ. Psycholog. Meas., 20, 37-46, 1960.

Gleick, P.: Water in Crisis: Paths to sustainable use, Ecol. Appl., 8, 571-579, 1998.

Gleick, P.: Soft Water Paths, Nature, 418, 373, 2002.

Gleick, P.: Global Freshwater Resources: Soft Path Solutions for the $21^{\text {st }}$ Century, Science, 302, 1524-1528, 2003.

Gober, P. and Kirkwood, C. W.: Vulnerability assessment of climate-induced water shortage in Phoenix, P. Natl. Acad. Sci., 107, 21295-21299, 2010.

Guest, G., Bunch, A., and Johnson, L.: How many interviews are enough? An experiment with data saturation and variability, Field Methods, 18, 59-82, 2006.

IWMI: Water for Food, Water for Life: Comprehensive Assessment of Water Management in Agriculture, edited by: Molden, D., Earthscan, London, UK, 2007.

Jacobs, I. and Turton, A.: Soft Path Thinking in Developing Countries: South Africa, in: Making the Most of the Water We Have: The Soft Path Approach to Water Management, Earthscan, London, UK, 228-233, 2009.

Jordaan, S., Stevens, C., and Brooks, D. B.: Removing Institutional Barriers to Soft Water Paths: Challenges and Solutions, in: Making the Most of the Water We Have: The Soft Path Approach to Water Management, Earthscan, London, UK, 147-162, 2009.

Klawitter, S.: Soft Path Thinking in Other Developed Countries: The European Union, in: Making the Most of the Water We Have: The Soft Path Approach to Water Management, Earthscan, London, UK, 211-217, 2009.

Krippendorff, K.: Content Analysis: An Introduction to its Methodology, Sage, Thousand Oaks, CA, 2012. 
Larson, K. L., White, D. D., Gober, P., Harlan, S., and Wutich, A.: Divergent perspectives on water resource sustainability in a public-policy-science context, Environ. Sci. Policy, 12, 10121023, 2009.

MacQueen, K. M., McLellan, E., Kay, K., and Milstein, B.: Codebook development for team-based qualitative analysis, Cult. Anthropol. Meth., 10, 31-36, 1998.

New Zealand Parliament: Household Incomes, Inequality, and Poverty, http://www.parliament.nz/ en-nz/parl-support/research-papers/00PlibCIP181/

household-incomes-inequality-and-poverty (last access: January 2014), 2013.

Ostrom, E.: Governing the Commons: The Evolution of Institutions for Collective Action, Cambridge University Press, Cambridge, UK, 1990.

Overpeck, J. and Udall, B.: Dry times ahead, Science, 328, 16421643, 2010.

Pahl-Wostl, C., Tàbara, D., Bouwen, R., Craps, M., Dewulf, A., Mostert, E., Rodder, D., and Taillieu, T.: The importance of social learning and culture for sustainable water management, Ecol. Econom. 64, 484-495, 2008.

Rijsberman, F. R.: Water Scarcity: Fact or Fiction?, Agr. Water Manage., 80, 5-22, 2006.

Seckler, D., Barker, R., and Amarasinghe, U.: Water Scarcity in the Twenty-first Century, Int. J. Water Resour. Develop., 15, 29-421, 1999.
Shakow, A. and Irwin, A.: Terms Reconsidered: Decoding Development Discourse, in: Dying for Growth: Global Inequity and the Health of the Poor, Common Courage Press, Monroe, ME, 44-61, 2002.

Smith, W. J. and Wang, Y. D.: Conservation rates: the best 'new' source of urban water during drought, Water Environ. J., 22, 100$116,2007$.

van der Zaag, P. and Gupta, J.: Scale issues in the governance of water storage projects, Water Resour. Res., 44, W10417, doi:10.1029/2007WR006364, 2008.

Wade, J. S.: The Future of Urban Water Services in Latin America, Bull. Latin Am. Res., 31, 207-221, 2012.

Wescoat, J. L., Headington, L., and Theobald, R.: Water and poverty in the United States, Geoforum, 38, 801-814, 2007.

World Bank: About Development, web.worldbank.org, FAQs, 2013a.

World Bank: World Development Indicators, http://data.worldbank. org/data-catalog/world-development-indicators (last access: January 2014), 2013b.

Wutich, A., Brewis, A., York, A. M., and Stotts, R.: Rules, Norms, and Injustice: A Cross-Cultural Study of Perceptions of Justice in Water Institutions, Soc. Nat. Resour., 26, 795-809, 2013.

Yin, R. K.: Case study research: Design and methods, Sage, Thousand Oaks, CA, 2009. 